\title{
Flagrando a ambiguidade da dogmática penal com a lupa criminológica: que garantismo é possível do compasso criminologia - penalismo crítico?
}

\author{
Vera Regina Pereira de Andrade ${ }^{1}$
}

Resumo: Desenvolvemos, neste artigo, uma análise da funcionalidade da dogmática penal no marco da modernidade e do sistema penal, sob o marco teórico central da Criminologia da reação social e crítica, apontando sua eficácia invertida e crise, bem como as possibilidades, então entreabertas, de uma nova relação entre Criminologia e dogmática penal (criminodogmática), potencializadora de um garantismo crítico e criminologicamente fundamentado, assente não mais sobre a legitimidade, mas sobre a deslegitimação da dogmática e do sistema penal moderno.

Palavras-chave: Modernidade. Dogmática penal. Sistema penal. Eficácia invertida. Crise de legitimidade. Criminologia crítica. Penalismo crítico.

\begin{abstract}
We develop in this article, an analysis of the functionality of Criminal Dogmatic in modernity and the criminal justice system, in the theoretical framework of the reaction center of Criminology and social criticism, pointing reversed its effectiveness and crisis, as well as possibilities, then ajar of a new relationship between Criminology and Criminal Dogmatic (crime dogmatic) potentiated in a critical guarantees criminology and reasoned, based on no more legitimacy, but on the illegitimacy of the dogmatic and the modern penal system.
\end{abstract}

Keywords: Modernity. Dogmatic criminal. Penal system. Effectively reversed. Legitimacy crisis. Critical criminology. Criminalists critical.

1 Mestre e doutora em Direito pelo Curso de Pós-graduação em Direito da Universidade Federal de Santa Catarina. Pós-doutora em Direito Penal e Criminologia pela Universidade de Buenos Aires - Argentina. Professora nos cursos de graduação, mestrado e doutorado em Direito da Universidade Federal de Santa Catarina Florianópolis - Brasil. 


\section{Introdução}

Desenvolvemos, aqui, uma análise criminológica crítica da dogmática Penal $^{2}$ concebida como um dos paradigmas científicos ${ }^{3}$ ambíguos, ${ }^{4}$ que integra o projeto e a trajetória da modernidade, no marco cultural onde o paradigma se originou no século XIX (a Europa continental), e naquele para o qual foi posteriormente transnacionalizado (como a América Latina) e permanece até hoje em vigor. E seu eixo de gravitação radica na análise das funções cumpridas e não cumpridas pela dogmática no âmbito do moderno sistema de justiça penal (ou sistema penal).

Em primeiro lugar, é necessário considerar que a matriz originária do paradigma dogmático de ciência penal encontra-se na Alemanha, sendo posteriormente recebido em outros Estados da Europa continental (Itália, Espanha, Portugal, Grécia, Holanda etc.) e da América Latina

2 O presente artigo, escrito originariamente para uma publicação chilena em homenagem ao Professor Juan Bustos Ramírez, com o título "a ambiguidade da dogmática penal e a ilusão de segurança jurídica: (re)desenhando o caminho de mão dupla”, é uma derivação de minha tese de doutoramento, que trata das funções da dogmática penal no marco do projeto da modernidade e do sistema penal moderno, e tanto o aprofundamento de seu conteúdo, quanto a bibliografia de sustentação, podem ser conferidos em: ANDRADE, Vera Regina Pereira de. A Ilusão de segurança jurídica: do controle da violência a violência do controle penal. 2. ed. Porto Alegre: Livraria do Advogado, 2003.

O marco teórico utilizado, além de elementos da obra de Boaventura de Sousa Santos, é a Criminologia desenvolvida com base no paradigma da reação social, desde seu momento fundacional, com as teorias do labelling approach, até sua maturação, com a Criminologia Crítica, e a historiografia dos sistemas punitivos. Daí nos referirmos à crítica criminológica e historiográfica.

3 Baseio-me aqui em elementos da teoria dos paradigmas de Thomas Kuhn (1979, p. 219), segundo o qual "um paradigma é aquilo que os membros de uma comunidade científica partilham. E, inversamente, uma comunidade científica consiste em homens que compartilham um paradigma." É neste sentido que me refiro ao paradigma dogmático de ciência penal. O signo "matriz" é usado, por sua vez, para designar uma concepção, um modelo ou um modelo que condiciona algo.

4 Conforme procurarei demonstrar, trata-se, a dogmática penal, não apenas de um saber visceralmente político, mas politicamente inscrito na contradição básica do controle penal moderno: exigências de dominação e legitimação, e exigências de segurança jurídica individual, e neste sentido sua identidade é a de um saber funcionalmente ambíguo do controle penal. 
(Brasil, Argentina, Costa Rica, Peru, Venezuela etc.), gozando, portanto, de uma marcada vigência nesta região, entre outras, do centro e da periferia do capitalismo mundial. Isto está a indicar que, segundo esta orientação centro-periferia, existe um potencial universalista do paradigma dogmático que lhe permite funcionar contextualizadamente e fora do lugar da origem; ou seja, para além da história da Europa em relação à América Latina e da história interna de cada Estado integrante de ambas as regiões. Em segundo lugar, constatação análoga se impõe relativamente ao modelo de sistema penal da modernidade, cujo potencial universalista atesta sua marcada vigência ${ }^{5}$ no conjunto das sociedades capitalistas.

Desta forma, embora a apreensão da diversidade regional e contextual no funcionamento dos sistemas penais e da dogmática penal seja um problema que não pode ser abordado senão histórica e empiricamente, a apreensão da regularidade estrutural de seu funcionamento como "modelos" hegemônicos que são, é um problema que pode ser adequadamente abordado teórica e globalmente. E esta regularidade está manifesta: a) pela existência de uma lógica de operacionalização dos sistemas penais que, embora submetida a variações regionais e contextuais, aparece como qualitativamente comum nas sociedades capitalistas; b) pela existência de funções comuns que, embora submetidas a diferentes apropriações regionais e contextuais, aparece como o fundamento dos sistemas penais nas sociedades capitalistas; c) pela inserção geral da dogmática penal na lógica de operacionalidade do moderno sistema penal.

\footnotetext{
5 Vigência que se estende, explicite-se, da comunidade científica (no sentido kuhneano) à aplicação do Direito, passando pela sua criação e ensino, sendo possível identificar três âmbitos de vigência e funcionalidade da dogmática penal: 1) como matriz dominante da educação jurídica, exercendo, através dos professores, uma função pedagógica; 2) como matriz da criação e reforma de leis penais, exercendo, através de estudos e comissões de juristas, uma função político-criminal de orientação das decisões legislativas; e 3) uma declarada função racionalizadora das decisões judiciais, precisamente a que constitui objeto de análise e problematização aqui, tendo por referência a vigência regular da dogmática no marco ao qual seu próprio discurso se vincula: a normalidade da vigência do Estado de Direito, pois os regimes de exceção, sejam os fascismos, nazismos ou ditaduras europeias e latino-americanas colocaram a vigência da dogmática penal, ao que tudo indica, total ou parcialmente sob suspensão.
} 


\section{A ambiguidade do projeto da modernidade e a "perversão matriarcal" da ciência}

SOUSA SANTOS, que tem desenvolvido uma das mais expressivas análises interpretativas da modernidade, sua trajetória e crise, caracteriza-a como um projeto sociocultural complexo, ambicioso e revolucionário, mas também internamente ambíguo.

Trata-se de um projeto ambicioso pela magnitude das promessas sendo marcado por uma profunda vocação racionalizadora da vida individual e coletiva e, neste sentido, caracterizado em sua matriz pela tentativa de um desenvolvimento equilibrado entre "regulação" e "emancipação humana", os dois grandes pilares em que se assenta. ${ }^{6}$ Mas, por isso mesmo, aparece tão apto à variabilidade quanto propenso a desenvolvimentos contraditórios. Pois, enquanto as exigências de regulação apontam para o potencial do projeto para os processos de concentração e exclusão, as promessas emancipatórias e as lógicas ou racionalidades construídas para sua realização apontam para suas potencialidades em cumprir, contraditoriamente, certas promessas de justiça, autonomia, solidariedade, identidade, liberdade e igualdade.

Assim,

[...] se por um lado, a amplitude de suas exigências abre um extenso horizonte para a inovação social e cultural; por outro lado a complexidade de seus elementos constitutivos faz com que o excesso de satisfação de algumas promessas assim como o déficit de realização de outras seja dificilmente evitável. Tal excesso e tal déficit estão inscritos na matriz deste paradigma. (SANTOS, 1989a, p. 240-241).

\footnotetext{
6 O pilar da regulação constitui-se do princípio do Estado (formulado destacadamente por Hobbes); do princípio do mercado (desenvolvido particularmente por Locke e Adam Smith); e do princípio da comunidade (que inspira a teoria social e política de Rousseau). O pilar da emancipação está constituído pela articulação entre três lógicas ou dimensões de racionalização e secularização da vida coletiva, tal como identificadas por Weber: a racionalidade moral-prática do Direito moderno; a racionalidade cognitivo-instrumental da ciência e da técnica modernas e a racionalidade estético-expressiva das artes e da literatura modernas (SOUSA SANTOS, 1989a, p. 225, 1991, p. 23).
} 
Emergindo como um projeto sociocultural entre o século XVI e o final do século XVIII, é apenas no final do século XVIII que a modernidade passa a se materializar. Este momento coincide com a aparição do capitalismo como modo de produção dominante nas sociedades capitalistas avançadas de hoje. Embora, pois, preceda ao aparecimento do capitalismo, desde então está vinculada ao seu desenvolvimento.

Sucede, então, que o pretendido equilíbrio entre regulação e emancipação, que deveria ser obtido pelo desenvolvimento harmonioso de cada um dos pilares e das suas inter-relações dinâmicas, que aparece ainda como aspiração decaída na máxima positivista "ordem e progresso", nunca foi conseguido. Na medida em que a trajetória da modernidade se identificou com a trajetória do capitalismo, o pilar da regulação - tornado pilar da regulação capitalista - veio a se fortalecer à custa do pilar da emancipação, num processo histórico não linear e contraditório, com oscilações recorrentes entre um e outro, como liberalismo e marxismo, capitalismo e socialismo, etc. (SOUSA SANTOS, 1989a, p. 225, 1990, p. 3, 1991).

Nesta perspectiva, é possível concluir que:

Tanto o excesso como o déficit de realização das promessas históricas explica nossa difícil situação atual que aparece, na superfície, como um período de crise, mas que, em um nível mais profundo, constitui um período de transição. Desde o momento em que todas as transições são parcialmente visíveis e parcialmente cegas, resulta impossível designar com propriedade nossa situação atual. Provavelmente isto explica porque a inadequada denominação 'pós-moderna' se tornou tão popular. Mas pela mesma razão este nome é autêntico na sua inadequação. (SOUSA SANTOS, 1989a, p. 223).

Assim, estamos perante uma situação nova que, à falta de melhor nome, pode-se designar transição pós-moderna. Seja como for, se um novo projeto sociocultural está a emergir nas sociedades do capitalismo avançado, sob os sintomas de crise que a modernidade parece inexoravelmente emitir, o contexto de oposição e justaposição 
entre o moderno e o "pós-moderno" testemunha antes de mais nada a necessidade de revisitar as próprias promessas da modernidade e avaliar os seus défices e excessos de realização, com os quais essa crise tem preliminarmente a ver.

E dado que a modernidade creditou à ciência e ao Direito um lugar central na instrumentalização do progresso e do seu projeto emancipatório, no qual os "direitos humanos aparecem como uma das principais promessas" (SOUSA SANTOS, 1989b, p. 3), o reencontro com o desempenho instrumental da ciência aparece, no balanço desta virada secular, como uma exigência de importância fundamental.

E nesse reencontro:

O ponto de partida do diagnóstico da Ciência moderna como problema reside na dupla verificação de que os excessos da modernidade que a Ciência prometeu corrigir, não só não foram corrigidos, como não cessam de se reproduzir em escala cada vez maior, e que os défices que a Ciência prometeu superar, não só não foram superados, como se multiplicaram e agravaram. Acresce que a Ciência não se limitou a ser ineficaz e parece, pelo contrário, ter contribuído, como se de uma perversão matriarcal se tratasse, para o agravamento das condições que procurou aliviar. (SOUSA SANTOS, 1991, p. 25).

\section{A dogmática penal no marco do projeto da modernidade: ambiguidade constitutiva e promessas}

Como se insere o paradigma dogmático de ciência penal no projeto da modernidade? Na medida em que o Estado aparece como um componente fundamental do pilar da regulação, ao mesmo tempo em que o reconhecimento do homem como sujeito de direito e os Direitos Humanos aparecem como uma exigência fundamental do pilar da emancipação, o projeto da modernidade se vê confrontado, desde o início, com a necessidade de equilibrar o poder monumental do Estado centralizado com a subjetividade atomizada dos indivíduos livres e iguais 
perante a lei, e de cuja tentativa a teoria política liberal aparece como a máxima expressão.

Daí que o poder penal do Estado moderno apareça recoberto de limites garantidores do indivíduo consubstanciados nos princípios constitucionais do Estado de Direito e do Direito penal e processual penal liberal, e que um princípio fundamental seja a exigência da generalização e igualdade no funcionamento do sistema penal em que este poder se institucionaliza. A garantia dos Direitos Humanos assume, então, um significado às avessas: não se trata de realizá-los ou solucionar os conflitos a eles relativos, mas de impedir a sua violação ali onde intervenha a violência punitiva institucionalizada: a dualidade regulação/ emancipação se traduz na exigência de um controle penal com segurança jurídica individual.

A dogmática penal representa, precisamente, o paradigma científico que emerge na modernidade prometendo assegurar este equilíbrio, limitando aquela violência e promovendo a segurança jurídica. O máximo contributo que pode prestar ao pilar da emancipação é, portanto, o do garantismo.

Consolidando-se historicamente na Europa continental desde a segunda metade do século XIX como um desdobramento disciplinar da dogmática jurídica e, a seguir, transnacionalizando-se, ela é assim concebida, pelos penalistas que protagonizaram e compartilham do seu paradigma (autoimagem) como "a" ciência do Direito penal que, tendo por objeto o Direito penal positivo vigente em um dado tempo e espaço, e por tarefa metódica (imanente) a construção de um sistema de conceitos elaborados a partir da interpretação do material normativo, segundo procedimentos intelectuais (lógico-formais) de coerência interna, teria uma função essencialmente prática: a de racionalizar $^{7}$ a aplicação judicial do Direito penal; ou seja, garantir a maior uniformização e previsibilidade possível das decisões judiciais e, consequentemente, uma aplicação igualitária (decisões iguais para casos iguais) do Direito penal que, subtraída à arbitrariedade, garantisse essencialmente a segurança jurídica e, por extensão, a justiça das decisões.

7 Racionalizar significa aqui preparar, pautar, programar delimitar ou prescrever. 


\section{A autoimagem funcional da dogmática penal: o retrato do garantismo}

Vimos esta promessa claramente enunciada desde o interior de suas próprias matrizes fundacionais, de forma exemplar e paradigmática, (porque desde então reiterada na comunidade jurídico-penal) no modelo liszteano de "Ciência Integral do Direito Penal".

Com efeito, neste modelo, a ciência penal, como ciência eminentemente prática - a serviço da administração da Justiça - somente poderia afirmar-se como ciência sistemática. É precisamente na ordenação dos conhecimentos na forma de um sistema que Liszt via a possibilidade de um domínio seguro e imediato dos casos particulares, apto a libertar a aplicação do Direito do acaso e da arbitrariedade. Procede, neste sentido, a observação de Roxin (1972, p. 18) quando afirma que com esta enunciação Liszt proferiu as palavras-chave que se repetem até hoje nos tratados e manuais dogmáticos para explicar a importância funcional da sistemática no Direito penal.

Assim Welzel (1987, p. 11), um dos mais significativos expoentes da dogmática germânica contemporânea reafirma aquela promessa funcional:

Missão da Ciência Penal é desenvolver e explicar o conteúdo das regras jurídicas em sua conexão interna, ou seja, 'sistematicamente'. Como ciência sistemática estabelece a base para uma administração de justiça igualitária e justa, já que só a compreensão das conexões internas do Direito liberam a sua aplicação do acaso e a arbitrariedade. Mas a ciência penal é uma ciência 'prática' não só porque ela serve à administração de justiça, mas também num sentido mais profundo, enquanto uma teoria do atuar humano justo e injusto, de modo que suas últimas raízes tocam os conceitos fundamentais da filosofia prática.

Em conferência pronunciada em 1966, respondendo especialmente aos ataques contra a dogmática alemã, de ter cultivado a disciplina jurídica do Direito penal como " a arte pela arte" sustenta que: 
[...] a divisão do delito em três diferentes graus de juízo e valoração estruturados uns sobre e, em seguida a outros [...] proporciona alto grau de racionalidade e segurança na aplicação do direito e ao diferenciar os graus de valoração, possibilita, além disso, um resultado final justo. [...] Efetivamente, este foi o desejo decisivo da dogmática. Já o havia entendido LISZT quando no prólogo da primeira edição de seu tratado (1881) exigiu 'conceitos claros e bem delimitados'.[...] A dogmática não foi cultivada 'unicamente' na Alemanha, como a arte pela arte, mas, sim, como firme baluarte contra invasões ideológicas. Isto aconteceu precisamente no Terceiro Reich. Nessa época a dogmática foi objeto de ataques severos, por ser 'um pensamento liberal de divisão'. A tempestade foi contida, precisamente, pela dogmática.[...] É significativo e, em certo sentido lamentável (para nós), que não tenha sido um alemão mas um espanhol, que tenha recordado aos ruidosos "críticos da reforma penal", o significado da dogmática [...]. (WELZEL,1974, p. 7-9)

O espanhol é precisamente Gimbernat Ordeig (1983, p. 27) e o que recorda, na década de 1970, é que:

A dogmática nos deve mostrar o que é devido com base no Direito. A dogmática jurídico-penal, pois, averigua o conteúdo do Direito penal, quais são os pressupostos que se darão para que entre em jogo um tipo penal, o que é que distingue um tipo de outro, onde acaba o comportamento impune e onde começa o punível. Torna possível, por conseguinte, ao assinalar limites e definir conceitos, uma aplicação segura e calculável do Direito Penal, torna possível subtraí-lo à irracionalidade, à arbitrariedade e à improvisação. Quanto menos desenvolvida esteja uma dogmática, mais imprevisível será a decisão dos tribunais, mais dependerão do acaso e de fatores incontroláveis a condenação ou a absolvição.

Desta forma, prossegue Gimbernat (1983, p. 30), em um autêntico Estado de Direito, a dogmática penal é um instrumento imprescindível para manter o Direito penal sob controle, para que a pena não chegue mais longe do que o legislador se propôs que chegue.

E nesta função garantidora depositava, na década de 1970, a convicção no futuro da dogmática penal: 
[...] Porque a existência do Direito Penal é imprescindível e não depende para nada da possibilidade de demonstrar a livre decisão humana no caso concreto, porque toda idéia jurídica progressiva necessita de uma formulação legal que será tanto mais perfeita e eficaz quanto mais alto for o nível científico-jurídico, porque uma ciência desenvolvida do Direito Penal é a que torna possível controlar os tipos penais, porque a pena é um meio necessário e terrível de política social, porque temos que viver com o Direito Penal, por tudo isso a dogmática jurídico-penal tem futuro. (GIMBERNAT, 1982, p. 32).

Também da dogmática alemã reitera Jescheck (apud ROXIN, 1972, p. 18) que:

[...] sem a articulação sistemática do conceito do delito, a solução de um caso jurídico permanece 'insegura e dependente de considerações sentimentais'. As características gerais do conceito do delito, que se resumem na teoria do delito, possibilitam, aliás, uma jurisprudência racional e uniforme, e ajudam, de um modo essencial, a garantir a segurança jurídica.

E da dogmática espanhola subscreve Muñoz Conde, (1975, p. 135136) que:

A Dogmática jurídico-penal [...] trata de averiguar o conteúdo das normas penais, seus supostos, suas conseqüências, de delimitar os fatos puníveis dos impunes, de conhecer, definitivamente, que é o que a vontade geral expressa na lei quer castigar e como quer fazê-lo. Nesse sentido a Dogmática jurídico-penal cumpre uma das mais importantes funções que tem encomendada à atividade jurídica em geral em um Estado de Direito: a de garantir os direitos fundamentais do indivíduo frente ao poder arbitrário do Estado que, embora se processe dentro de uns limites, necessita do controle e da segurança desses limites.

Cantero (1977, p. 15-16) por sua vez, afirma que a missão da dogmática penal: 
[...] é desenvolver sistematicamente e interpretar, em sua conexão interna, o conteúdo das normas que constituem o ordenamento jurídico-penal. Ao cumprir esta missão a Ciência do Direito Penal colabora para uma reta administração de justiça, pois - como observou WELZEL - só o conhecimento do Direito em sua conexão interna destaca sua aplicação sobre o acaso e a arbitrariedade.

Da dogmática penal brasileira, essa promessa funcional pode ser ilustrada na fala de Fragoso (1986, p. 11) ao afirmar que:8

A Dogmática Jurídica é a Ciência da norma jurídica, que visa ao seu conhecimento sistemático, para permitir a aplicação igualitária e justa do Direito. Mas isto é alcançado, superando-se a simples atividade dos glossadores, através da reconstrução científica do direito vigente.

A dogmática penal afirma-se, portanto, desde sua gênese alemã e italiana, até hereditariedade que na América Latina e no Brasil alcançou, como uma ciência sistemática e eminentemente prática, a serviço de uma administração racional da justiça penal, que teria como subproduto a segurança jurídica e a justiça das decisões judiciais. Podemos demarcar, pois, no discurso dogmático, uma função declarada e oficialmente perseguida, a qual denominamos função instrumental racionalizadoral garantidora.

E foi precisamente porque centralizou a promessa de igualdade e segurança jurídica, tão cara ao ideário do Estado de Direito, que no modelo integrado de ciências penais recebeu a coroa e a faixa de rainha, reinando com absoluta soberania, enquanto todos os demais saberes, integrativos do amplo espectro das chamadas ciências criminais, se consolariam, e bem, com faixas de segundas e terceiras princesas. Assim o foi com a Criminologia positivista e a política criminal, que passaram ao estatuto de ciências auxiliares da dogmática penal.

8 A respeito, ver ainda, entre muitos outros, Solano Navarro (1990, p. 183), Batista (1990, p. 117), Carrasquilla (1988, p. 73-74); Pozo (1988, p. 39). 
E é em nome da segurança jurídica, que aparece no discurso da dogmática penal como a ideia-síntese de suas promessas, que ela tem pretendido justificar, historicamente, a importância de sua já secular existência e o seu ideal de ciência. E ao mesmo tempo em que o discurso da segurança jurídica aparece fortemente enraizado e consolidado na mentalidade dogmática em geral, considera-se, a contrario sensu, que a ausência de uma dogmática penal implicaria o império da insegurança jurídica.

Desta forma, na sua tarefa de elaboração técnico-jurídica do Direito penal vigente, a dogmática, partindo da interpretação das normas penais e explicando-as em sua conexão interna, desenvolve uma arquitetônica teórica nucleada no conceito analítico de crime e nas categorias tipicidade, ilicitude e culpabiliade, que, consubstanciada em requisitos objetivos e subjetivos para a imputação de responsabilidade penal pelos juízes e tribunais, objetiva vincular o horizonte decisório à legalidade e ao Direito penal do fato-crime; ou seja, vincular as decisões judiciais à lei e à conduta do autor de um fatocrime, objetiva e subjetivamente considerada em relação a este, pretendendo exorcizar, por esta via, a submissão do imputado à arbitrariedade judicial. A esta construção conceitual denominamos código tecnológico. Mas o discurso dogmático é portador, simultaneamente, de um código ideológico, que com ele se dialetiza, constituindo o sentido e o limite da simbologia e da instrumentalidade dogmática. O discurso dogmático, enquanto conjunto de representações e símbolos, conforma um imaginário ou senso comum idealizado e neutralizador do sistema penal: coloca em circulação social o ideário e a crença na segurança jurídica, contendo, a um só tempo, uma dimensão (positiva) de produção de sentido e uma dimensão (negativa) de ocultação/inversão.

\section{Em busca da segurança jurídica prometida}

Revisitar suas promessas significa então indagar: mas, em que medida têm sido cumpridas as funções declaradas da dogmática penal na trajetória da modernidade? Tem a dogmática penal conseguido garantir os Direitos Humanos individuais contra a violência punitiva? Tem sido possível controlar o delito com igualdade e segurança jurídica? Encontra 
congruência na práxis do sistema penal o discurso garantidor secular em nome do qual a dogmática penal fala e pretende legitimar o seu próprio ideal de ciência? E é pelo cumprimento da função racionalizadora/ garantidora declarada que se explica sua marcada vigência histórica ou ela potencializa e cumpre funções distintas das prometidas?

Tais são as questões centrais que objetivamos responder e cujas respostas implicam exercer o que denominamos de "controle funcional" da dogmática penal. ${ }^{9}$ Como a dogmática penal funcionalmente relacionase com o sistema penal - uma vez que elaborou promessas para serem efetivadas em seu âmbito - a análise deste, em especial de seu real funcionamento, aparece como o referencial básico para o pretendido controle. Impõe-se, neste sentido, a necessidade de uma análise relacional apta a comparar as promessas dogmáticas com a operacionalidade do sistema penal enquanto conjunto de ações e decisões e, em especial, com as decisões judiciais, pois é esta análise contrastiva que possibilita emitir juízos de (in)congruência entre operacionalidade e programação do sistema penal; ou seja, verificar se o sistema opera ou não no marco da programação normativa e dogmática e, em especial, se as decisões judiciais são de fato dogmaticamente pautadas e, por extensão, igualitárias, seguras e justas.

A perspectiva assumida é a de que a resposta às questões enunciadas e a compreensão da situação presente da dogmática penal e dos desafios que está hoje interpelada a responder, demandam mais do que nunca revisitar o paradigma desde suas bases fundacionais, pois é esse reencontro que possibilita captar as contradições que, estando na base da relação funcional entre dogmática e sistema penal, condiciona a sua trajetória histórica. Nesta esteira, se é verdade que a modernidade não pode fornecer a solução para os problemas de nosso tempo histórico, "não é menos verdade que somente ela permite pensá-la”. (SANTOS, 1991, p. 27).

Reinterpretar a dogmática penal nestes termos implica assim uma tentativa de olhar o paradigma, como o faz o Professor Bustos Ramírez, com uma inserção distinta da tradicional. Implica redescobrir nele potencialidades humanistas e virtualidades. Mas implica também

9 A respeito das bases deste controle, ver Andrade (2003, p. 31-36). 
falar de poder, violência e dominação, enquanto elementos que, embora sistematicamente neutralizados e recusados pelo seu discurso, imprimem-lhe significação plena. Necessário, pois, retomar a inserção da dogmática penal no marco do projeto da modernidade e do sistema penal, consolidando as seguintes indicações:

1) O sistema penal é um dos locus em que o desenvolvimento contraditório da modernidade vem a se materializar com intensidade, e a explicação global para tal desenvolvimento remete à distinção entre funções declaradas e funções latentes e reais potencializadas desde a fundação do projeto.

2) Ao mesmo tempo em que a dogmática penal se insere oficialmente no projeto da modernidade como um saber instrumental para a realização de uma das suas principais promessas e expressa a sua vocação racionalizadora, ela se insere, igualmente, na sua ambiguidade interna e potencialidade de seu desenvolvimento contraditório, que se materializa particularmente no sistema penal.

3) a dogmática penal não integra o projeto e a trajetória da modernidade como uma ciência do Direito penal, isto é, como uma instância científica externa "sobre" ele, mas como uma instância interna do sistema penal e, enquanto tal é coconstitutiva de sua identidade e integra o seu real funcionamento e desenvolvimento contraditório, inserindo-se naquele diagnóstico da ciência moderna como problema.

Com base no exposto, procuramos responder aos interrogantes originariamente formulados mediante uma análise interpretativa da dogmática penal como "ciência" (funcionalmente ambígua) do sistema penal, e, portanto, como uma "ciência" do controle social sob o fio condutor das suas funções declaradas (promessas) e latentes e dos seus défices e excessos de realização, apontando a contradição que marca geneticamente a dogmática penal entre promessas humanitárias garantidoras e a captura por exigências reguladoras do sistema penal, a partir da qual se desnudam suas funções latentes. 


\section{Encontrando a "perversão matriarcal" e a" eficácia invertida": do controle da violência à violência do controle penal}

O objetivo geral perseguido, que formulamos aqui como hipótese central, é demonstrar que há, no âmbito do sistema penal, um profundo déficit histórico de cumprimento das funções declaradas da dogmática penal, ao mesmo tempo em que o cumprimento excessivo de outras funções (simbólicas e instrumentais) não apenas distintas, mas inversas às oficialmente declaradas, que seu próprio paradigma, latente e ambiguamente tem potencializado desde sua gênese histórica. E são estas, desenvolvidas com êxito por dentro do fracasso de suas funções declaradas, que explicam sua relação funcional com a realidade social e sua marcada vigência histórica. As promessas da dogmática penal não apenas se inscrevem na longa agenda das promessas não cumpridas da modernidade, mas na própria "perversão matriarcal" da ciência moderna.

Com efeito, se as promessas da modernidade eram as de generalização e igualdade no exercício da função punitiva, a dogmática penal e a técnica jurídica correspondente não conseguiriam até agora assegurar esta promessa (BARATTA, 1993), senão vejamos.

Parece suficientemente demonstrado, por outro lado, o caráter irreversível desta lógica e a impossibilidade de a operacionalidade dos sistemas penais adequar-se à sua programação, já que constitui uma marca estrutural do seu exercício de poder que não pode ser eliminada sem a própria supressão dos sistemas penais.

O exercício de poder dos sistemas penais nas sociedades capitalistas é marcado, para além de suas intervenções contingentes, por uma lógica estrutural de operacionalização que, implicando na violação encoberta (seletividade) e aberta (arbitrariedade) dos direitos humanos, não apenas viola a sua programação normativa - os princípios constitucionais do Estado de Direito e do Direito penal e processual penal liberais - e teleológica (fins atribuídos ao Direito penal e à pena) mas é, num plano mais profundo, oposta a ambas, caracterizando-se por uma eficácia instrumental invertida à qual uma eficácia simbólica (legitimadora) confere sustentação. A potencialidade deste desenvolvimento contraditório está, 
todavia, inscrita nas bases fundacionais do próprio sistema, expressando a tensão entre um projeto jurídico-penal tendencialmente igualitário e um sistema social fundado na desigualdade real de acesso à riqueza e ao poder; e entre a igualdade formal e a desigualdade substancial. O limite do sistema é, neste sentido, o limite da própria sociedade.

Globalmente considerada, pois, esta lógica se traduz numa subprodução (déficit) de garantismo e numa sobreprodução (excesso) de seletividade/arbítrio e legitimação, cuja violência institucional expressa e mantém um nexo funcional mais profundo com a reprodução das desigualdades sociais, isto é, com a violência estrutural. E desse desequilíbrio resulta a grave crise de legitimidade experimentada pelo moderno sistema penal, não obstante a sobrevivência de sua autolegitimação oficial associada a demandas político-criminais e sociais relegitimadoras de sua intervenção. É o chamado eficietismo penal, materializado através de teorias como a das "janelas quebradas" e dos movimentos de lei e ordem e das políticas de tolerância zero.

\section{Défices e excessos: subprodução de segurança (fracasso garantidor) $x$ sobreprodução de seletividade e legitimação (sucesso regulatório). A hegemonia na ambiguidade}

Na medida em que a dogmática penal é uma instância interna do sistema penal, ela tem sido capturada pela sua lógica de funcionamento, integrando-a e coparticipando dela ao invés de controlá-la. Assim, o desequilíbrio global do exercício de poder do sistema penal acaba deixando a dogmática prisioneira da própria fantasia que cria, condicionando seus próprios limites e possibilidades; isto é, seus défices e excessos funcionais. A real funcionalidade dogmática não se encontra, por outro lado, controlada.

Visibilizado, pela crítica criminológica e historiográfica, que tal lógica, inserindo-se no continuum do controle social global, radica na criminalização seletiva de pessoas - a seletividade - de acordo com seu status social e não na incriminação igualitária de condutas, objetiva e subjetivamente consideradas em relação ao fato-crime, conforme o 
evidencia a clientela do sistema penal, são as seguintes as conclusões parciais a pontuar:

1) Se os casos que chegam à agência judicial são o produto de uma seletividade estrutural (controle social informal, criminalização primária, incapacidade operacionalizadora estrutural do sistema penal, criminalização secundária) que lhe é submetida à decisão, e à qual ela tem regularmente convalidado e consolidado, coparticipando da construção seletiva da criminalidade.

2) Se a regularidade da distribuição seletiva da criminalidade (imunização x criminalização) e, particularmente, das decisões judiciais seletivas, é explicada pela influência de um código social (second code) latente integrado por mecanismos de seleção, dentre os quais têm se destacado: a importância central dos estereótipos de criminosos e vítimas, associados às teorias de todos os dias (every day theories) dos quais são portadores os juízes e a opinião pública, além de processos derivados da estrutura organizacional e comunicativa do sistema penal que reenviam ao status social do processado em detrimento do instrumental dogmático construído para a imputação da responsabilidade penal e administradas através da técnica jurídico-penal que deveria reenviar à sua conduta.

3) Se o second code (código ideológico latente) judicial é o que geralmente pauta e condiciona, efetivamente e a priori, as decisões, mas não se submete à obrigação de motivação fática e jurídica da sentença, permanecendo, por isso, invisível e fora do controle público ("macrocosmos invisível").

4) Se o código dogmático (tecnológico) do Direito penal do fato, ao revés, com seu poder pautador esvaziado, é o que aparece regularmente e a posteriori, junto com os códigos legais, na motivação formal e na justificação da legalidade das decisões seletivas ("microcosmos visível"), permitindo recolocar normas e "conceitos" no lugar daqueles preconceitos, operando como uma cobertura decisória do (contra) Direito penal do autor.

5) Se a uniformização e previsibilidade das decisões judiciais aparecem, consequentemente, como probabilidade de que alguns 
serão selecionados pelo sistema e outros não, dependendo de seu status social e/ou das exigências do poder constituído; a igualdade formal aparece como desigualdade real, a segurança como in-segurança, que beneficia determinados grupos e classes sociais em detrimento de outros, isto é, como in-justiça.

6) Se, enfim, tal colonização do código tecnológico dogmático pelo second code judicial autoriza a considerar as características nas quais se baseia a motivação formal da sentença de condenação (como os conceitos de imputabilidade e culpabilidade) como qualidades atribuídas ao sujeito, os juízos de imputação de responsabilidade penal nele baseados como juízos atributivos, e a sentença penal como atribuição de responsabilidade penal.

Todos esses argumentos concorrem para uma conclusão genérica fundamental: entre a evidência empírica de que o código tecnológico da dogmática tem sido utilizado para fundamentar juridicamente e justificar a legalidade das decisões judiciais e a evidência empírica de sua incapacidade racionalizadora (pautadora do conteúdo decisório) para a gestação de decisões igualitárias (soluções iguais para casos iguais) seguras e justas, somente resta a hipótese de que tem concorrido para instrumentalizar e racionalizar as decisões seletivas, acabando por fornecer a elas uma justificação técnica de base científica, legitimando-as e, na sua esteira, a totalidade do exercício de poder do sistema penal, pois é em virtude mesmo da pré-programação legislativa e dogmática da ação jurisdicional que o sistema penal se legitima pela legalidade.

Ora, a sentença penal é, efetivamente, tão mais complexa que uma exclusão/imputação de responsabilidade penal baseada nos códigos legais e no código tecnológico dogmático, que não cobre o second code judicial e os processos de influência que, excluídos e predominando sobre aquele, condicionam, latentemente, a seletividade das decisões judiciais.

Assim, enquanto a dogmática penal centraliza a construção do sistema garantidor na conduta do autor, edificando uma técnica de imputação de responsabilidade penal pautada por requisitos objetivos (conduta típica e antijurídica) e subjetivos (culpabilidade do agente imputável) e demarcando um horizonte decisório vinculado à legalidade 
e ao fato-crime cometido, em que a subjetividade do autor apenas deve ingressar como vontade (dolosa ou culposa) e culpabilidade em relação ao fato (Direito penal do fato); são precisamente as variáveis relativas à pessoa do autor e outras, exorcizadas pela dogmática pela porta da frente de sua construção conceitual que ingressam pela porta dos fundos e preponderam nas decisões judiciais.

Trata-se, em definitivo, de um (contra) Direito penal do autor, operando latentemente por dentro de um Direito penal do fato, e submetendo-o até deixá-lo imerso nele, sendo condicionante da seletividade que a dogmática penal não consegue exorcizar, acabando, paradoxalmente, por racionalizar.

Nesta perspectiva, a radiografia interna dos sistemas penais vigentes é uma radiografia direta e um testemunho definitivo do profundo déficit histórico de cumprimento da função instrumental racionalizadora/ garantidora, prometida pela dogmática penal (subprodução de segurança jurídica); ao mesmo tempo é também uma radiografia indireta do cumprimento excessivo de uma função instrumental racionalizadora da criminalização seletiva e de uma função legitimadora do funcionamento global do sistema penal (sobreprodução de seletividade e legitimação) que seu próprio paradigma, latente e ambiguamente, tem potencializado.

Enquanto sua eficácia instrumental tem sido excessivamente inversa à declarada, sua eficácia garantidora tem sido simbólica, devido à aptidão do código ideológico do discurso dogmático para (re) produzir um certo número de representações; ou seja, para confirmar a instrumentalidade declarada subproduzida, ocultando a instrumentalidade sobreproduzida e gerando a "ilusão" de segurança jurídica. Concorre, pois, de maneira não desprezível, para socializar a crença e produzir um consenso (real ou aparente) em torno de uma imagem ideal e mistificadora do funcionamento do sistema, ao mesmo tempo em que oculta sua real funcionalidade. E este simbolismo tem gerado efeitos legitimadores não apenas do subsistema da justiça, mas de todo o sistema penal, acompanhando e sustentando aquela eficácia instrumental invertida (reprodução ideológica do sistema).

O déficit de tutela real dos Direitos Humanos é assim compensado pela criação, no público, de uma ilusão de segurança jurídica e de um 
sentimento de confiança no Direito penal e nas instituições de controle que têm uma base real cada vez mais escassa (BARATTA, 1982a).

O controle penal capitalista, que a dogmática se propõe a racionalizar, em nome dos Direitos Humanos e da segurança jurídica exigidos pelo Estado de Direito e o Direito penal liberal, é o mesmo controle que ela utiliza para operacionalizar e legitimar, mesmo que opere seletivamente e viole, sistematicamente, os Direitos Humanos, configurando um suporte importante na manutenção da desigual distribuição da riqueza e do poder.

Consequentemente, a relação funcional da dogmática com a realidade social e sua marcada vigência histórica se explica pelo cumprimento excessivo de uma função instrumental latente e oposta à declarada (instrumentalidade de eficácia invertida) e de uma função simbólica confirmadora desta (declaração de eficácia simbólica), não obstante seu déficit empírico. Até aqui tem se desenvolvido, exitosamente, como ciência da legitimação.

E o sucesso no cumprimento de tais funções instrumentais e simbólicas por dentro do fracasso de suas funções declaradas tem sido tamanho que ela se mantém vigente contra mais de um século de problematizações e críticas. Parafraseando o diagnóstico de Sousa Santos sobre a ciência moderna, o diagnóstico da dogmática penal como problema reside, consequentemente, na dupla verificação de que os excessos (de violência punitiva) que prometeu minimizar não só não o foram como não cessam de se reproduzir e de que os défices (de garantia individual) que prometeu superar não só não foram superados, como se multiplicaram. Acrescenta-se que, ao longo de sua vigência, a dogmática penal não apenas tem sido incapaz de administrar o desenvolvimento contraditório do projeto da modernidade que se materializa no sistema penal (maximização da violência e minimização das garantias), mas ao que tudo indica, tem, paradoxalmente, coparticipado no desequilíbrio havido, via técnica jurídica.

A "perversão matriarcal" e o paradoxo da dogmática penal na trajetória da modernidade consiste assim em que ela transita da promessa de controle da violência à captura e coparticipação na violência do 
controle penal, e sua vocação pautadora humanista aparece colonizada e submersa por sua vocação técnica e legitimadora.

Se apreendemos a modernidade, o sistema penal e sua dogmática desde a ótica da contradição básica entre exigências de dominação e legitimação (pilar da regulação) e exigências humanistas (pilar da emancipação), não parecem restar dúvidas de que, na lógica global de funcionamento do sistema penal, a ambiguidade dogmática tem sido excessivamente apropriada pelas exigências do primeiro pilar. A segurança do homem tem sido colonizada e hegemonizada pela exigência de segurança do próprio sistema social que o sistema penal contribui para reproduzir, exercendo seu poder contra alguns homens.

\section{O porquê do fracasso}

Do pilar do garantismo, o grande problema que subsiste é que a dogmática penal ainda não renunciou à sua onipotência, quando se vê hoje demonstrado que a centralidade e o superpoder garantidor por ela assumido no marco de um modelo integrado de ciência penal, foi um poder excessivamente superior à sua intrínseca capacidade.

Se os espaços de garantismo que o sistema penal possibilita são, por sua intrínseca violência institucional, muito vulneráveis - e uma Justiça Penal recoberta de garantias formais parece ser um reconhecimento inequívoco disto - hoje está evidenciado que a apropriação dos potenciais garantidores da dogmática penal, que subsistem, todavia, no simbolismo de suas promessas, para uma ação rigorosamente correta do sistema penal, somente pode se dar em situações contingentes e excepcionais (sempre pontuais, relativamente a casos específicos), mas não têm o poder de reverter a lógica da seletividade e a arbitrariedade do sistema; não pode modificar seu funcionamento estrutural e resolver a crise de legitimidade que o afeta, ainda que por essas contradições.

Por outro lado, se o desequilíbrio do sistema penal, do qual a dogmática penal acaba prisioneira, encontra seu limite na própria sociedade, não podendo ser atribuído unicamente às suas limitações, a incapacidade até aqui demonstrada para controlar a violência e garantir 
os direitos humanos, isto é, seu déficit funcional de segurança jurídica, remonta, de qualquer modo, à sua própria debilidade analítica e idealismo; ou seja, à profunda separação cognoscitiva entre dogmática e realidade social e aos seus défices epistemológicos.

É que, em definitivo, há uma distância abissal entre a abrangência e complexidade da fenomenologia do sistema de controle penal e a apreensão reducionista e idealizada que dela faz a dogmática penal, excluindo os elementos e fatores reais que integram e condicionam a fenomenologia e o exercício de poder do sistema. E seu campo de intervenção e poder garantidor nesta fenomenologia é muito menor do que o dogmaticamente idealizado e prometido. Ela capta e pretende racionalizar as decisões judiciais mediante sua abstração normativa e descontextualização do sistema penal, superpondo à imagem do sistema como ele é e funciona, a imagem do Direito penal como ele deveria ser, e tratando-o como se de fato fosse. O problema, portanto, não aparece na tentativa de racionalização decisória, mas nos pressupostos idealizados em que esta tentativa se apoia.

Desta forma, enquanto os sistemas penais seguem a marcha de sua violência aberta e encoberta, contra os sujeitos que vivem em simbiose com ele, e vivemos o império da insegurança jurídica "com" uma dogmática penal simbólica, esta segue ancorada numa visão idealizada (ideologizada) do funcionamento do Direito penal, na premissa de sua legitimidade e na ilusão de segurança jurídica. E as escolas de Direito e os tribunais seguem sustentando, no prolongamento da comunidade científica, a sua reprodução. Pois, no fundo, a fantasia da segurança jurídica não deixa de ser também a fantasia de poder que alimenta a onipotência dogmática e dos próprios operadores jurídicos formados na sua tradição.

De outra parte, se a separação cognoscitiva da dogmática penal com a realidade social, o atraso teórico e a falsificação empírica de seu discurso, ou seja, seus défices epistemológicos condicionam, até certo ponto, seu déficit funcional, constata-se, ao mesmo tempo, que tal idealismo e falsidade integram seu código ideológico, que tem sido fundamental à legitimação (reprodução ideológica) do sistema penal. É 
precisamente por sobrepor à imagem real do sistema penal uma imagem ideal do funcionamento do Direito penal, que o discurso dogmático tem tido uma eficácia simbólica legitimadora.

Até certo ponto, pois, tal idealismo e falsidade têm sido duplamente funcionais, condicionando, relativamente, tanto a subprodução de garantismo, quanto a sobreprodução de legitimação; tanto os défices quanto os excessos funcionais da dogmática penal, pois, condicionam, em proporção diametralmente oposta, seus limites garantidores e seus potenciais legitimadores.

\section{Da crise de legitimidade à crise de paradigma}

Se a complexidade da vigência dogmática como instância do sistema penal radica, pois, em que seu fracasso desde o pilar do garantismo é acompanhado do seu sucesso desde o pilar da regulação, esta mesma complexidade se transporta inteiramente do plano de sua vigência para o de sua crise. A dogmática penal aparece, desta perspectiva, igualmente prisioneira do processo de dupla via a que o desenvolvimento contraditório do sistema penal conduziu: uma grave crise de legitimidade que não afeta, todavia, sua sobrevivência histórica e a continuidade de sua autolegitimação oficial, na qual a dogmática continua sendo uma discursividade fundamental.

Desta forma, se desde o pilar da regulação, a dogmática continua se mostrando funcional à reprodução do sistema, desde o pilar do garantismo e de suas funções declaradas, ela experimenta, contudo, uma profunda crise de legitimidade que, exposta pelos seus défices e excessos funcionais, decorre da própria crise de legitimidade do sistema penal: a deslegitimação do sistema arrasta consigo a deslegitimação da dogmática e do próprio modelo integrado de ciência penal a que se vincula na modernidade, e o problema de sua justificação retorna, paradoxalmente, à posição fetal: como conter os excessos de violência e superar os défices de garantismo já não da antiga, mas da moderna Justiça penal?

Reconduzida, contudo, da dimensão funcional à epistemológicocognoscitiva, tal crise de legitimidade pode ser vista, num plano mais 
profundo, como sinalizadora de uma crise de paradigma, pois se o efeito cumulativo gerado pela dificuldade histórica da dogmática penal resolver os problemas práticos a que se propôs - cumprir as promessas - do interior de seus pressupostos e conhecimento, aponta para o esgotamento e bloqueio destes para a funcionalização prática declarada, e o próprio paradigma é que passa a se revelar como fonte última de problemas e incongruências, pois, não apenas aparece demonstrada a incapacidade de dogmática penal manter o equilíbrio do sistema, como aparecem com maior razão esgotadas as possibilidades de ela conter o seu desequilíbrio e reverter a sua crise de legitimidade, que aparecem como irreversíveis. Neste sentido, nem o déficit de garantismo do sistema, nem o seu déficit cognoscitivo parecem recuperáveis desde o seu interior. A crise da dogmática penal é, assim, uma crise complexa, que está em curso, mas parece distante de consumada.

\section{Os caminhos da superação e o compasso criminologia - penalismo críticos: redesenhando o caminho de mão dupla}

A contemporânea discussão sobre o futuro da dogmática penal deve enfrentar, portanto, pelo menos dois níveis: um nível macro, vinculado à sua conexão funcional com o sistema penal e a conexão funcional deste com as estruturas sociais, e um nível micro, que se conecta com a sua específica identidade epistemológica, cultural e ideológica.

Desta última perspectiva, a possibilidade de que, no desdobramento desta crise, seja realizada uma transformação na dogmática penal e sua relação funcional com o sistema penal tendente a compensar o pilar dos Direitos Humanos e a interagir com o próprio sistema - depende do deslocamento de sua separação à sua aproximação e abertura cognoscitiva para a realidade social; de seu monólogo e isolamento acadêmico à busca do diálogo interdisciplinar; da reprodução à autocrítica e suspensão do dogmatismo na ciência penal, e da dogmatização à problematização de suas próprias premissas.

E como a relação da dogmática com a realidade social é uma relação mediada pelo sistema penal no qual se insere, é apenas a recepção 
dos resultados teórico-empíricos, sobretudo criminológicos, sobre o real funcionamento do sistema, que pode conduzir a este deslocamento. A possibilidade desta transformação depende assim, de maneira relevante, da relação que se estabeleça entre dogmática penal e criminologia crítica no marco de um novo modelo integrado de ciência penal.

O ponto da mutação já se encontra, desta perspectiva, instaurado. Ele radica no aprofundamento e radicalização do caminho aberto pela parceria criminologia-penalismo crítico, cujo elo reside no desenvolvimento do aspecto crítico da criminologia ao encontro do aspecto garantidor do Direito penal dogmático e vice-versa; ou seja, no caminho do que denominamos um garantismo criminologicamente fundamentado, a curto e médio prazo, inserido no horizonte utópico de superação do atual sistema de controle penal.

Pois é ela que tem protagonizado o aludido deslocamento e, a partir dele, as bases da reconstrução da dogmática penal e do modelo oficial integrado de ciência penal, partindo de uma inversão das próprias premissas sobre as quais assenta a dogmática penal: da assunção da legitimidade à assunção da perda de legitimidade do sistema e da dogmática penal, e do esgotamento do seu discurso e poder para bloquear a violência ascencional do sistema.

Resgatada a autonomia do saber criminológico, consequentemente, uma discussão contemporânea sobre as relações entre dogmática penal e criminologia somente pode dar-se sobre novas bases (ANYIAR DE CASTRO, 1987, p. 87-88).

Retornamos assim a uma clássica e delicada questão, pois, se as relações entre ambas têm sido historicamente pouco cordiais e sujeitas a fortes tensões (RAMIREZ, 1987, p. 523), estas aparecem revigoradas ao se indagar sobre a possibilidade de uma nova relação, ao ponto de Zaffaroni (1982, p. 46) ter afirmado, há certo tempo, que "no fundo parecem coincidir e de fato coincidem numa incomunicabilidade absoluta".

Para logo aduzir, contudo, que "[...] há tanto irracionalismo na atitude dos penalistas que rechaçam indiscriminadamente toda a criminologia chamada crítica e inclusive toda a criminologia atual, como 
na dos criminólogos radicais que negam em bloco toda a legitimidade do direito penal" (ZAFFARONI, 1982, p. 46).

Por outro lado, como observa Olmo (1987, p. 38-39), hoje podemos constatar que essa incomunicabilidade não é mais absoluta, na medida em que "estão surgindo uma série de penalistas que têm iniciado uma interessante reflexão crítica não apenas sobre o direito penal e o direito em geral, mas também sobre a criminologia crítica, que pode resultar muito útil para a concreção desta criminologia. Incumbe ao criminólogo sua reflexão crítica da criminologia crítica e do direito penal [...]”' (OLMO, 1987, p. 38-39)

Nesta perspectiva, como também pondera Bustos Ramirez (1987, p. 538), "o criminólogo crítico será um penalista crítico e o penalista também um criminólogo crítico".

Com efeito, a quebra desta incomunicabilidade está hoje instaurada por obra de criminólogos e penalistas críticos que, colocando em suspensão seja o radicalismo criminológico, seja o radicalismo dogmático (que ignora ou repudia em bloco a criminologia crítica), tem protagonizado uma nova relação, na qual visualizamos, sem prejuízo de outros enfoques, duas faces, a saber, uma relativa à recepção (desde o interior do próprio penalismo) ou à projeção (por criminólogos críticos) dos dados sobre o sistema penal para a análise da dogmática, cujos resultados obtidos têm remetido para (e esta é a segunda e correlata face) o debate relativo à sua reconstrução/transformação que acaba retomando, sob um novo prisma, o clássico debate do final do século XIX sobre as (im)possibilidades de um novo modelo integrado de ciência penal. ${ }^{10}$

Neste sentido, pode-se dizer que, independentemente da transformação dogmática e de um novo modelo disciplinar que esta nova interação

10 Nesta interação entre criminologia e penalismo críticos, podem situar-se, sem pretensões de exaustividade: Bustos Ramirez (1987); Baratta (1982b, 1991a); Bergalli (1984a); Zaffaroni (1989, 1991); Bacigalupo (1982); Anyar de Castro (1987); Garcia Mendez (19--); Carrasquilla (1984); Conorado Franco (1990); Navarro Solano (1990); Tosca Hernandez (1991); Clemente (1991); Sola Dueñas (1982); Ferrajoli (1986, 1989); Perfecto Ibanez (1988); Cirino dos Santos (1985); Nilo Batista (1991).

É importante aduzir também que esta interação não tem se limitado ao nível da produção teórica mas abrange o engajamento em movimentos de reforma da Justiça e de defesa dos Direitos Humanos (em especial dos menores) em países europeus e latino-americanos. 
possa protagonizar, está hoje aberta e explorada a recepção da crítica historiográfica e criminológica do sistema penal também desde o interior da própria dogmática penal por segmentos, embora minoritários, de penalistas críticos que, atuando como "sujeitos" desta recepção, podem inclusive ser considerados como "cientistas extraordinários" no sentido kuhneano.

Não visualizamos, portanto, aqui, uma nova relação entre ciência e objeto, na qual a dogmática penal seja convertida em objeto da criminologia crítica (objeto criminológico) vista como um saber externo, alheio e de confrontação a ela. Visualizamos uma interação teóricoprática que se situa, portanto, no momento de interregno entre um modelo oficial integrado de ciência penal epistemológica e funcionalmente deslegitimado (ainda que oficialmente vigente), e a busca de uma nova integração superadora, e cujo pressuposto é a perda de legitimidade do sistema penal ao qual esse modelo se vincula.

Ponto fundamental então a destacar é que, neste interregno, um dos elos fundamentais da referida interação têm sido, ao que nos parece, o desenvolvimento do aspecto crítico da criminologia ao encontro do aspecto garantidor do Direito penal dogmático e vice-versa; ou seja, um "garantismo crítico" entendido como vigilância sobre o (des) respeito aos Direitos Humanos no marco do funcionamento efetivo (e não idealizado) do sistema penal. Assim, se o projeto de transformação do controle penal da criminologia crítica não se limita ao garantismo, é necessário insistir com Aniyar de Castro (1987, p. 88-89) que, apesar do que pensam alguns juristas, ela não trata de negar o Direito: interessa-se, antes, por dotá-lo de novos conteúdos e resgatar sua vertente garantidora.

Referindo-se, por exemplo, à investigação sobre sistemas penais e Direitos Humanos dirigida por Zaffaroni (1984a, b) na América Latina, Anyiar de Castro (1987, p. 93-94) visualizava nela, precisamente, as potencialidades de um aprofundamento daquele elo (garantismo crítico) ao asseverar que:

[...] a primeira conseqüência relevante de um projeto como este está, nos parece, em um refrescamento das possibilidades de colaboração, senão de integração, entre a Criminologia - que não pode ser senão a crítica -, e um direito penal (ou se quer ser mais 
preciso, uma ciência penal), também crítico. O 'garantismo', ou respeito, vigilância e garantia dos Direitos Humanos, se converteria assim na zona coincidente de ambos os círculos e em objetivo de alto nível na escala de prioridades de ambas as disciplinas.

Não parece ser desprovido de sentido ver então no conhecimento produzido no marco desta parceria uma "ciência extraordinária" no sentido kuhneano. Pois tal é precisamente a atividade que se desenvolve quando um paradigma - o dogmático - começa a dar sinais de crise e até que seja substituído por outro. O cientista extraordinário é tal precisamente por ter problematizado o modelo científico tradicional e rompido com ele, ao perceber suas falhas e anomalias, buscando um novo instrumental para resolvê-las e chegando eventualmente a propor e até a impor um novo paradigma. Ele não lida com quebra-cabeças, mas com autênticos problemas para os quais o paradigma vigente não oferece meios de solução e exigem um novo paradigma de acordo com o qual seja possível tratá-los e resolvê-los.

Delineia-se assim o deslocamento de um garantismo abstrato, que segue orientando a dogmática penal, enquanto "ciência normal", para um garantismo crítico e criminologicamente fundado, que orienta a tematização da "ciência extraordinária", a qual resgata e reatualiza, por sua vez, as próprias promessas da dogmática penal para a modernidade, repensando-as sobre as contradições do tempo presente.

\section{Referências}

ANDRADE, Vera Regina Pereira de. A Ilusão de segurança jurídica: do controle da violência à violência do controle penal. 2. ed. Porto Alegre: Livraria do Advogado, 2003.

ANIYAR DE CASTRO. Criminologia de la Liberación. Maracaibo: Universidad de Zulia, 1987.

BACIGALUPO, Enrique. Relaciones entre la dogmática penal y la criminologia. In: MIR PUIG, Santiago (Org.) Derecho penal y ciencias sociales. Bellaterra: Universida Autónoma de Barcelona, 1982. p. 53-70. 
BARATTA, Alessandro.Criminologia y dogmática penal: pasado y futuro del modelo integral de la ciencia penal. In: MIR PUIG, Santiago et al. Política criminal y reforma del derecho penal. Bogotá: Temis, 1982a. p. 28-63.

. Observaciones sobre las funciones de la cárcel en la producción de las relaciones sociales de desigualdad. Nuevo Foro Penal. Bogotá, n.15, p.737-749, jul./set. 1982 b.

. Democracia, dogmática penal e criminologia. Texto inédito. Conferência apresentada no II Encontro Internacional de Direito Alternativo. Florianópolis, set. 1993.

BATISTA, Nilo. Introdução crítica ao direito penal brasileiro. Rio de Janeiro: Revan, 1990.

BERGALLI, Roberto. Sentido y contenido de una sociologia del control penal para América Latina. In: Criminologia crítica. I Seminário. Medellin: Universidad de Medellin, agosto de 1984a.

; BUSTOS RAMIREZ, Juan (Org.). El pensamiento

criminológico I. um análisis crítico. Barcelona: Península, 1983.

BUSTOS RAMÍREZ, Juan. Estado y control: la ideologia del control y el control de la ideologia. In: BERGALLI, Roberto; RAMÍREZ, Juan Bustos (Org.). El Pensamento criminológico II. Estado y control. Barcelona: Península, 1983. p.11-35.

. Política criminal y dogmática. In: BERGALLI, Roberto; BUSTOS, Juan (Org.). El poder penal del Estado. Homenage a Hilde Kaufmann. Buenos Aires: Depalma, 1985. p. 123-154.

. Control social y sistema penal. Barcelona: PPU, 1987.

. Necessidad de la pena, función simbólica y bien juurídico medio ambiente. Revista Hispanoamericana, Barcelona, n. 1, p. 101-109, 1991. BUSTOS RAMÍREZ, Juan; HORMAZÁBAL, H. Pena y Estado. Papers. Barcelona, n. 13, p. 97-128, 1980.

CANTERO, José A. Sainz. La ciencia del derecho penal y su evolución. Barcelona: Bosch, 1977.

CIRINO DOS SANTOS, Juarez. Direito penal: a nova parte geral. Rio de Janeiro: Forense, 1985. 
CONORADO FRANCO, Fernando. Dogmática jurídica y Criminologia crítica. In: ALVAREZ G., Ana Josefina et al. Criminologia crítica. México: Universidad Autónoma de Querétaro, 1990. p.65-70.

CARRASQUILLA, Juan Fernández.Panorama de las relaciones entre el derecho penal, la política criminal y la criminologia en el ámbito de la justicia penal. Nuevo Foro Penal, Bogotá, n. 25, p. 287-291, jul./set. 1984.

. Los derechos humanos como barrera de contención y criterio autoregulador del poder punitivo. Nuevo Foro Penal, Colombia, n. 39, p. 58-88, jul./set. 1988 .

CLEMENTE, Martin. Em busca de una nueva dogmática. aproximación a una perspectiva criminológica de la dogmática jurídico-penal. No hay Derecho. Buenos Aires, n. 3, p. 29, abr./mayo 1991.

FERRAJOLI, Luigi..El derecho penal mínimo. Poder y Control. Barcelona, n. 0, p. 25-48, 1986.

. Diritto e ragione. Teoria del garantismo penale. Roma: Laterza, 1989.

FRAGOSO, Heleno Cláudio. Lições de Direito penal: a nova parte geral. v. 1. Rio de Janeiro: Forense, 1986.

GARCÍA MÉNDEZ, Emilio _.La violencia doméstica y el sistema de la justicia penal: pautas para un derecho penal mínimo. Doctrina Penal, Buenos Aires, n. 10, p. 227-238, [19--].

GIMBERNAT ORDEIG, Enrique. Tiene futuro la dogmática juridicopenal? Colombia: Temis, 1983.

HERNANDEZ A., Tosca. La ideologización del delito y de la pena. Caracas: Universidad Central de Venezuela, 1977.

MUÑOZ COÑDE, Francisco. Introducción al derecho penal. Barcelona: Bosch, 1975.

. Para uma ciência crítica do direito penal. Revista de Direito Penal. Rio de Janeiro: Forense, n.25, p.7-12, jan./jun. 1979. 
NAVARRO SOLANO, Sônia. Control socia y dogmática penal. In: OLIVEIRA, Edmundo (Org.). Criminologia crítica. Pará: Cejup, 1990. p. 179-188.

OLMO, Rosa de. Criminologia y derecho penal. aspectos gnoseológicos de una relación necesaria en la america latina actual. Separata de Doctrina Penal, Buenos Aires, n. 37, p. 23-43, ene./mar. 1987.

PERFECTO IBAÑEZ, Andrés. Sobre democracia y justicia penal. Capítulo criminológico. Maracaibo: Universidad del Zulia, n. 16, p. 5967, 1988.

POZO, José Hurtado. El principio de legalidad, la relación de causalidad y la culpabilidad: reflexiones sobre la dogmática penal. Nuevo Foro Penal, Colombia, n. 39, p. 11-41,ene./mar. 1988.

ROXIN, Claus. Política criminal y sistema del derecho penal. Tradução por Francisco Muñoz Conde. Barcelona: Bosch, 1972.

SOUSA SANTOS, Boaventura. Estado e sociedade na semiperiferia do sistema mundial: o caso português. Análise Social, Lisboa, n. 87-89, p. 869-901, mar. 1985.

SOUSA SANTOS, Boaventura. La transición postmoderna: Derecho y politica. Cuadernos de Filosofia del Derecho, Alicante, n. 6, p. 223-263, 1989a.

. Os direitos humanos na pós-modernidade. Direito e sociedade, Coimbra, n. 4, p. 3-12, mar. 1989 b.

. O Estado e o direito na transição pós-moderna. Revista Crítica de Ciências Sociais, Coimbra, n. 30, p. 13-43, jun. 1990.

. Ciência. In: CARRILHO, Manuel Maria (Org.). Dicionário do pensamento contemporâneo. Lisboa: Dom Quixote, 1991. p. 23-43.

SOLA DUEÑAS, Angel de. Política Social y Política criminal. In: BERGALLI, Roberto; BUSTOS RAMIREZ, Juan (Org.). Pensamento criminológico II. Barcelona: Península, 1982. p. 245-268.

ZAFFARONI, Eugenio Raúl. Política criminal latinoamericana. Buenos Aires: Hammurabi, 1982. 
ZAFFARONI, Eugenio Raúl. Sistemas penales y derechos humanos en América Latina (primer informe). Buenos Aires: Depalma, 1984a.

. Sistemas penales y derechos humanos en América Latina (segundo informe). Buenos Aires: Depalma, 1984b.

. La crítica al Derecho Penal y el porvenir de la Dogmática Jurídica. In: CUESTA, Jose Luis de la et. al. (Comp.). Criminologia y Derecho Penal ao servicio de la persona. Libro-Homenage al profesor Antonio Berinstain. San Sebastián: Instituto Vasco de Criminologia, 1989. . El sistema penal en los países de América Latina. In: ARAÚJO JR., João Marcelo de (Org.). Sistema penal para o terceiro milênio. Rio de Janeiro: Revan, 1991a. p. 221-236.

. Em busca das penas perdidas: a perda de legitimidade do sistema penal. Tradução por Vânia Romano Pedrosa e Amir Lopez da Conceiçao. Rio de Janeiro: Revan, $1991 b$.

WELZEL, Hans. A dogmática no direito penal. Tradução por Yolanda Catão. Revista de Direito penal. São Paulo, n.13-14, p. 7-12, 1974.

. Derecho penal alemán. Tradução por Juan Bustos Ramírez e Sergio Yánez Pérez. Chile: Editorial Jurídica de Chile, 1987. 